\title{
El método IBI en la enseñanza de ELE. Aplicación de la gamificación en el Camino de Santiago
}

\author{
Álvaro GARCÍA MORENO \\ Universidad Nebrija \\ agarciam20@alumnos.nebrija.es \\ Santiago SeVilla VAlLEJo \\ Universidad de Alcalá \\ santiago.sevilla@uah.es
}

\begin{abstract}
Resumen: Los cambios recientes producidos en el ámbito de la educación y, particularmente, en la adquisición de segundas lenguas, como son la utilización de metodologías activas y el viraje en el foco de atención de la gramática hacia el vocabulario, son el punto de partida de esta propuesta de innovación didáctica para una clase de ELE. En concreto, este trabajo parte de un método pedagógico donde el aprendizaje de vocabulario se sitúa en el centro del mismo, el método IBI (input-based incremental), y de cómo una herramienta didáctica, la gamificación, puede aumentar su efectividad tanto en resultados de aprendizaje como en términos actitudinales. Para ello, este trabajo realiza una propuesta de innovación didáctica que consiste en seis lecciones enmarcadas en el recorrido del Camino de Santiago inglés.
\end{abstract}

Palabras clave: aprendizaje de vocabulario, español como lengua extranjera, input-based incremental (IBI), gamificación.

\section{The IBI approach to Spanish as a Foreign Language learning. An application of gamification based on the Camino de Santiago}

Abstract: Recent changes in the field of education and, particularly, in the acquisition of second languages, such as the use of active learning and the shift in the focus of attention from grammar to vocabulary, are the origin of this proposal of didactic innovation for a class of Spanish as a foreign language. Specifically, this work is based on a pedagogical method where vocabulary is the centre of learning, the IBI (input-based incremental) method, and how a didactic tool, gamification, can increase its effectiveness both in learning outcomes and in attitudinal terms. To achieve this, the present work makes a proposal of didactic innovation that consists of six lessons framed in the English route of Camino de Santiago.

Keywords: vocabulary learning, Spanish as a Foreign Language, input-based incremental (IBI), gamification. 


\section{Introducción}

En las últimas décadas se ha producido un cambio de paradigma en las metodologías de adquisición de segundas lenguas (L2), virando desde un foco centrado, principalmente, en la gramática, a otro centrado en el vocabulario. Desde los años 90, este enfoque toma fuerza en la literatura académica con trabajos tan importantes como el de Willis en 1990 y el de Lewis en 1993, que abren la puerta al desarrollo de nuevos métodos que pueden resultar de interés para su puesta en práctica en el aula, como es el caso del método IBI (input-based incremental) de Barcroft en 2012.

Este método resulta muy interesante, principalmente, por cuatro razones: es flexible y fácilmente aplicable en clase debido a su diseño, tiene una base teórico-práctica que sustenta los principios por los que se rige, y fomenta la inclusión de aplicaciones derivadas de nuevos estudios en el terreno del aprendizaje de vocabulario. Es por este último motivo por el que parece interesante incluir la gamificación a este método como técnica innovadora en el terreno de la adquisición de segundas lenguas.

Junto con este viraje en el foco de atención hacia el vocabulario, la metodología actual en las clases de idiomas se encamina hacia un abandono cada vez mayor de la educación tradicional, centrando el proceso de enseñanza en el alumno, con metodologías activas que permiten el desarrollo de sus destrezas comunicativas. En este sentido, la gamificación es una herramienta didáctica que puede resultar de utilidad para favorecer la comunicación, la interacción entre los estudiantes y con el profesor, y dar respuesta a los nuevos estilos educativos.

Otra de las razones importantes, que se debe tener en cuenta al emplear la gamificación en el contexto del aprendizaje de segundas lenguas, es sus posibilidades como elemento motivador. Uno de los factores que más impacto tiene en el aprendizaje es la motivación, por lo que conseguir un aumento de la misma en los grupos de estudiantes resulta de mucha utilidad para cualquier instructor en el transcurso normal de su asignatura.

Asimismo, la gamificación, al ser un concepto de relativa actualidad en la investigación académica, ha sido poco explorado, por el momento, en el terreno de la adquisición de lenguas, y, menos aún, en el del aprendizaje de vocabulario. De igual forma, la poca literatura relativa a la adquisición de segundas lenguas se ha centrado, principalmente, en el inglés, y en contextos digitales. Como consecuencia, resulta interesante realizar una propuesta didáctica como esta, que se enmarca en una clase de español para extranjeros, en la que además se aprovechan los recursos habituales que suelen tener este tipo de aulas.

\section{Método IBI}

En las tres últimas décadas ha habido un gran aumento de literatura académica relacionada con el vocabulario dentro del campo de la adquisición de segundas lenguas (Willis, 1990; Lewis, 1993; Nattinger y De Carrico, 1992; Boers y Lindstromberg, 2009; Barcroft, 2012). Esto se debe al papel preponderante que ha ido adquiriendo la enseñanza de léxico en este ámbito. En este sentido, el método IBI (input-based incremental) trata de aplicar de forma efectiva los numerosos avances teóricos y prácticos sobre el léxico a la enseñanza de segundas lenguas, especialmente aquellos vinculados al procesamiento del input léxico (Barcroft, 2015: 113).

Asimismo, el método IBI también propone una convergencia de distintos modelos de pensamiento con respecto a la enseñanza de vocabulario dentro de la adquisición de 
segundas lenguas, como son el de la enseñanza implícita (ocasional) y el de la enseñanza explícita (intencional). Este método defiende la necesidad de un aprendizaje explícito e implícito de vocabulario como parte de un currículo comunicativo basado en tareas y contenido (Barcroft, 2015: 113).

Sentados los cimientos del método IBI, a continuación se enumeran los diez principios por los que se rige, que están sustentados en una base teórico-práctica específica para su inclusión:

1. Desarrollar e implementar un plan de adquisición de vocabulario.

2. Presentar nuevas palabras de forma repetida y frecuente en el input.

3. Promover el aprendizaje de vocabulario tanto intencional como ocasional.

4. Utilizar un input comprensible y significativo al presentar nuevas palabras.

5. Presentar nuevas palabras de forma llamativa.

6. Limitar la producción forzada sin acceso al significado durante las primeras etapas.

7. Limitar la elaboración semántica forzada durante las primeras etapas.

8. Promover progresivamente el aprendizaje de los significados y usos de las palabras que sean específicos de la L2.

9. Progresar de actividades menos exigentes a actividades más exigentes.

10. Aplicar los resultados de investigaciones que tengan implicaciones directas para la enseñanza de vocabulario.

Por otro lado, Barcroft (2012: 41) incluye una lista de verificación de utilidad para quien quiera implementar una lección basada en el método IBI en el aula. Esta lista consta de siete puntos, que se explicitarán en el apartado 5.1., y que sirven como guía para que los instructores puedan confirmar que no están olvidando ningún punto clave del método en su programación. Dado su carácter de verificación, la propuesta lectiva incluirá un comentario comprobando su ajuste al método IBI.

\section{Gamificación en el aprendizaje}

La gamificación es un término de relativa actualidad que ha emergido como una nueva tendencia en la literatura académica desde 2010, y que hace referencia al uso de mecánicas y componentes de los juegos en ámbitos que no están relacionados con el juego (Simões et al., 2013: 346). En el ámbito de la educación, donde se enmarca este artículo, la gamificación ha sido definida por Simões et al. (2013: 347) como «the use of game elements in a learning environment». Otros autores, como Dehghanzadeh et al. (2019: 3), añaden otros elementos a la definición y hablan de la gamificación de la educación como un término relativamente nuevo referido a menudo como «the use of game elements in non-game situations to create enjoyable, fun, and motivating learning experiences for learners». En esta misma línea, Kapp (2012: 10) dice que la gamificación supone «using game-based mechanics, aesthetics and game thinking to engage people, motivate action, promote learning, and solve problems».

Sin embargo, pese a los esfuerzos de distintos autores por definir y delimitar este constructo, la gamificación es un término que a menudo se confunde en la literatura académica con otros conceptos, como el de los juegos serios (serious games) y el aprendizaje basado en el juego (game-based learning). En línea con lo expuesto por Van Eck (2006: 6-7), una actividad gamificada difiere de los otros dos conceptos en que esta no contiene necesariamente todos los elementos y mecánicas de los juegos, mientras que 
los enfoques anteriormente expuestos sí que lo hacen en mayor o menor medida. La gamificación utiliza elementos y dinámicas del juego para facilitar el aprendizaje, mientras que en el aprendizaje basado en el juego y en los juegos serios, el proceso de aprendizaje se deriva del juego en sí. En esta propuesta hemos tenido en cuenta la jerarquía de los elementos del juego de Werbach y Hunter (2012: 78-82) que propone su división en tres categorías por orden decreciente de abstracción: dinámicas, mecánicas y componentes, que a su vez están conectadas entre sí.

\subsection{Beneficios de la gamificación en la educación}

En el ámbito de la educación, son numerosas las investigaciones que plantean beneficios asociados a la gamificación de una actividad de aprendizaje (Ortiz-Colón et al., 2018). A continuación, vamos a ver los más interesantes para nuestro trabajo.

\subsubsection{Motivación y compromiso}

La motivación se demuestra mediante la elección del propio estudiante de comprometerse con una actividad determinada, gracias a su esfuerzo y persistencia. Este aspecto es muy interesante para los docentes, ya que la motivación y el compromiso son unos de los principales retos a afrontar en los centros educativos en la actualidad (Ortiz-Colón et al., 2018: 6). En este artículo, vamos a ver dos tipos de motivación interesantes a tener en cuenta en el ámbito académico: extrínseca e intrínseca.

La motivación extrínseca es una motivación externa al individuo, es aquella implicada en el aprendizaje como medio para lograr un fin a través de premios y castigos (Buckley y Doyle, 2016: 1165). Según Soriano (2011: 169), este tipo de motivación es el que se ha usado tradicionalmente en el sistema educativo, pero no siempre con resultados positivos. Dentro de las actividades gamificadas, este tipo de motivación va de la mano de las recompensas, como los puntos, insignias o tablas de clasificación.

Por otro lado, la motivación intrínseca es aquella que implica que los estudiantes estén interesados en lo que aprenden y en el proceso de aprendizaje en sí, sin esperar estímulos externos (Buckley y Doyle, 2016: 1165). A pesar de que la gamificación es una herramienta que habitualmente intenta incrementar la motivación extrínseca, Landers y Landers (2014: 779-780) han demostrado que la aplicación de determinados componentes de la gamificación puede tener un efecto positivo en la motivación intrínseca.

En este sentido, para mejorar la comprensión y motivación a la lectura de los estudiantes, Alonso Tapia (2005: 81-89) propone algunas claves que nos pueden servir de utilidad para su aplicación en nuestra propuesta didáctica gamificada. La primera de las claves supone establecer un propósito claro a la actividad. Darles un objetivo, cuánto más interesante mejor, les puede guiar y motivar para realizar el esfuerzo que suponen las tareas planteadas. Este punto expuesto por Alonso Tapia (2015: 82) está en consonancia con la teoría de establecimiento de objetivos (goal-setting theory).

La segunda clave supone la activación de los conocimientos previos. En este sentido, cuanto más conozca el alumno sobre la temática, localización, personajes o cualquier elemento propio de la actividad, mayor será su comprensión.

El último de los puntos es el uso de elementos gráficos como ilustraciones, mapas, etc. para facilitar el entendimiento al alumno. Por ejemplo, en nuestra propuesta, al tener como contexto el Camino de Santiago, les puede facilitar la comprensión del mismo el uso de mapas e imágenes que contextualicen cada una de las etapas. 
Al ser uno de los conceptos más utilizados para medir la eficacia de la gamificación en el aprendizaje, son muchos los estudios empíricos que lo emplean. Así, en el aprendizaje de segundas lenguas, son varios los estudios que remiten una mayor motivación debido al empleo de actividades gamificadas. Entre estos artículos se encuentran el de Abrams y Walsh (2015), el de Baldauf et al. (2017), el de Hasegawa et al. (2015), el de Kétyi (2016) y el de Zhou et al. (2017), que informan de resultados positivos en términos de motivación y compromiso usando distintos elementos de la gamificación como las recompensas, las tablas de clasificación, la narrativa, la cooperación o la progresión, entre otros.

\subsubsection{Competición y colaboración}

El aprendizaje competitivo es un tema de gran controversia en la literatura académica. Mientras que hay autores que lo defienden argumentando un aumento de la motivación por parte de los estudiantes (Lawrence, 2004; Fasli y Michalakopoloulos, 2005), hay otros que creen que el estrés derivado de esta competición es más perjudicial que los posibles beneficios que pueda tener (Lam et al., 2001; Vockell, 2004). Sin embargo, hay un amplio consenso sobre que la competición por equipos es menos nociva y puede resultar una forma efectiva de aprendizaje para los estudiantes (Cantador, 2016: 68). La gamificación permite este tipo de aprendizaje a través de las mecánicas diseñadas, conjugando cierta competición con trabajo colaborativo, como es el caso de la propuesta didáctica desarrollada en este trabajo.

Cantador (2016: 68) se centra en el concepto de competición saludable, acuñado por Shindler en 2007, que dice que una competición es saludable si se trata de una actividad corta en la que los premios de los vencedores no sean sustanciales, y cuyo foco esté centrado en el aprendizaje y no en los resultados. Este tipo de competición implicaría una motivación intrínseca, principalmente, ya que los premios no deben suponer un verdadero estímulo para el estudiante.

Por otro lado, el aprendizaje cooperativo es una metodología que consiste en organizar las actividades de tal forma que los estudiantes tengan que trabajar en equipo para completar las tareas (Cantador, 2016: 71). El aprendizaje cooperativo es un enfoque muy aceptado por la comunidad educativa, ya que favorece el trabajo en equipos pequeños y heterogéneos a los que se les establece una meta común.

\subsubsection{Libertad para fallar}

Los juegos normalmente animan a los jugadores a experimentar sin miedo a que el fallo cause un daño irreversible en la partida. Incorporar esta libertad para cometer errores resulta muy efectivo para incrementar el compromiso de los estudiantes (Stott y Neustaedter, 2013: 1).

Según Gallego et al. (2014: 19), sin cometer errores es muy difícil llegar a un aprendizaje profundo y duradero. En cualquier sistema formativo se tienden a penalizar. Por el contrario, los entornos de juego favorecen esta libertad para el fallo, reduciendo el estrés que se pueda producir en una clase tradicional. Esta libertad para fallar está íntimamente ligada al feedback o retroalimentación. Para que la naturalización del error sea más efectiva, es importante dar a los estudiantes un feedback que les permita probar, experimentar y ver las consecuencias de sus decisiones, favoreciendo un aprendizaje basado en la idea de prueba y error (Gallego et al., 2014: 14).

\subsubsection{Resultados académicos}


Además de los beneficios referidos en los estudios sobre las actitudes de los aprendientes, también son interesantes de incluir los resultados académicos ligados a la adquisición de segundas lenguas. En este sentido, el estudio de Castañeda y Cho (2016: 1201) señaló una mejora de la precisión de los estudiantes al conjugar verbos en español gracias a la gamificación.

De forma más específica, en lo que concierne al aprendizaje de vocabulario en una segunda lengua, son varios los estudios que mostraron una mejora en la retención y la adquisición de vocabulario (Lui, 2014; Llerena Medina y Rodríguez Hurtado, 2017; Kétyi, 2016). Es interesante tener en cuenta los resultados positivos en el aprendizaje específico de vocabulario que pueden ofrecer las actividades gamificadas para su inclusión en un programa siguiendo el método IBI, en consonancia con el principio número diez, que anima a los instructores a aplicar los resultados de investigaciones que tengan implicaciones directas para la enseñanza de vocabulario.

\section{Diseño de la investigación y metodología}

El artículo realizado consiste en una propuesta de innovación didáctica. Esta propuesta se basa en gamificar un programa de aprendizaje de vocabulario siguiendo el método IBI. Gracias a esta herramienta didáctica, se busca una mayor motivación y compromiso de los estudiantes que les lleve a mejorar sus resultados en cuanto a adquisición y retención de vocabulario.

El Camino de Santiago nos sirve como contexto para desarrollar esta aplicación siguiendo como base la idea llevada a cabo por el curso online de español Spanish Language Route. Este curso se basa en un videojuego serio que trata de desarrollar las habilidades comunicativas de los aprendientes de español utilizando como contexto el Camino de Santiago. En nuestro trabajo, el Camino de Santiago también nos servirá como fondo para desarrollar las lecciones implementadas en el aula con el objetivo de mejorar la adquisición y retención de vocabulario de una forma innovadora y motivadora.

Este trabajo está planteado para una clase de español para extranjeros de nivel intermedio, B1. Para el desarrollo e implementación del plan de adquisición de vocabulario, siguiendo el primero de los principios del método IBI, hemos utilizado el libro de texto centrado en el léxico de Baralo et al. (2009). Nuestras lecciones se sirven de este manual como base para elegir las palabras meta ${ }^{1}$ de cada una de las mismas, más algunas otras añadidas por su utilidad, y presentadas en grupos temáticos en vez de en grupos semánticos, como recomiendan los estudios de Finkbeiner y Nicol en 2003, y de Tinkham en 1997 (en Barcroft, 2012: 39).

Los objetivos del presente trabajo son los siguientes:

- Objetivo general: desarrollar una propuesta didáctica que promueva una mayor adquisición y retención de vocabulario dentro de las clases de español para extranjeros.

- Objetivos específicos:

- Emplear una metodología innovadora y motivadora.

\footnotetext{
${ }^{1}$ Nótese que al hablar de palabras meta también se incluyen unidades léxicas complejas como pueden ser las fórmulas rutinarias, las colocaciones, los compuestos sintagmáticos, las locuciones y otras expresiones idiomáticas.
} 
- Crear un diseño realizable y flexible que pueda ser adaptado a las especificidades de cada grupo.

- Utilizar los recursos materiales y económicos habituales en este tipo de enseñanza.

\section{Propuesta didáctica}

Antes de empezar la propuesta, realizaremos una breve explicación a los estudiantes para que sepan en qué va a consistir el programa a desarrollar durante las siguientes clases, de forma que tengan claros los objetivos, en consonancia con el primer punto clave de Alonso Tapia (2005) para mejorar la comprensión y motivación de los estudiantes, y la teoría de establecimiento de objetivos (goal-setting theory).

Dividiremos a la clase en grupos heterogéneos de cuatro miembros cada uno. Les contaremos que todos somos peregrinos que tenemos que salir desde Ferrol y llegar a Santiago de Compostela siguiendo el Camino de Santiago inglés. Para poder avanzar, de etapa en etapa, tendremos que aprender vocabulario, que trataremos de relacionar con Galicia, comunidad autónoma donde se ubica esta ruta, y con el camino en sí, para que la experiencia sea más inmersiva y la narrativa sea coherente. Cada lección será una etapa del Camino de Santiago inglés, que consta de un total de seis.

Todas las lecciones tendrán la misma estructura: presentación de la etapa del camino, con imágenes y gráficos que les permitirán situarse mejor, aprendizaje de las palabras meta siguiendo el método IBI, y una prueba final que llevará a los equipos a conseguir una insignia, una concha del peregrino. Hay tres tipos de concha: la de oro, la de plata y la de bronce. Varios equipos pueden conseguir la insignia de oro en la misma prueba, ya que se busca una competición "saludable", en línea con lo propuesto por Cantador (2016), por lo que la recompensa no es un verdadero estímulo en sí, centrándonos más en el propio aprendizaje, y combinando competición con trabajo colaborativo.

Una vez explicado el juego, trataremos de ponerles en contexto con una pequeña introducción sobre el origen del Camino de Santiago, el recorrido que vamos a realizar, los lugares por donde pasa, etc., en consonancia con el segundo punto clave para la motivación de Alonso Tapia (2005). En una pared de la clase o en una pizarra colgaremos la ruta para ir señalando día a día donde nos encontramos, último punto clave señalado en este trabajo por Alonso Tapia (2005), la utilización de material gráfico como complemento. Este tipo de información se puede encontrar en webs como www.pilgrim.es y www.vivecamino.com, entre otras.

Por otro lado, cada grupo elegirá su avatar dentro de los personajes mitológicos del folclore y la cultura gallega, como por ejemplo, la Santa Compaña, las meigas o los trasgos. El profesor les deberá dar varias opciones, explicando de forma breve en qué consiste cada uno. Cada grupo elegirá su preferencia.

En este sentido, Werbach y Hunter (2012: 39) citan a Huizinga y su reconocida obra Homo Ludens de 1949, haciendo referencia al círculo mágico, un espacio que sirve para separar el mundo real de aquel creado en el juego. Es un espacio en el que el jugador acepta las normas del juego sin tener en cuenta las reglas que configuran el mundo real. El avatar permite a los jugadores tener una experiencia más inmersiva en el juego, potenciando su imaginación (Dalmases, 2017: 21). 
En cuanto a los elementos de competición dentro del juego, esta propuesta cuenta con insignias y tablas de clasificación. Las insignias, como hemos explicado anteriormente, son las conchas del peregrino de oro, plata y bronce. Estas insignias, creadas por el profesor, bien de cartulina o bien de papel, se pondrán en una tabla de clasificación que se colgará en la clase. Para favorecer que la competición sea saludable y evitar la comparación social, esta tabla será fija, añadiendo al lado de cada grupo las insignias que consiga. Todos los grupos conseguirán insignias en cada una de las etapas, ya sea de oro, plata o bronce, pero no habrá posiciones, por lo que no habrá ganadores ni perdedores. Estas insignias pueden tener un efecto motivacional positivo en el compromiso de los estudiantes hacia la actividad, como demuestran los estudios de Denny (2013), Domínguez et al. (2013) y Hakulinen et al. (2013).

Teniendo en cuenta la clasificación de los elementos de gamificación establecida por Werbach y Hunter (2012), en la tabla 1 se recogen los componentes, mecánicas y dinámicas empleadas en la propuesta didáctica, y cómo se corresponden entre sí.

\begin{tabular}{|l|l|l|}
\hline Componentes & Mecánicas & Dinámicas \\
\hline Equipos & Cooperación & Relaciones \\
\hline Niveles & Retos & Progresión \\
\hline Tablas de clasificación & $\begin{array}{l}\text { Competición } \\
\text { Feedback } \\
\text { Recompensas } \\
\text { Retos }\end{array}$ & $\begin{array}{l}\text { Competitividad } \\
\text { Progresión } \\
\text { Curiosidad }\end{array}$ \\
\hline Insignias & Logros & Narrativa \\
\hline Avatares & & Elaborach propia apatir de \\
\hline
\end{tabular}

Tabla 1. Componentes, mecánicas y dinámicas de la propuesta didáctica. Elaboración propia a partir de la clasificación de Werbach y Hunter (2012: 78-82)

Al ser una propuesta didáctica flexible, el cronograma de cada uno de los pasos y la evaluación del aprendizaje quedarán a decisión del profesor que imparta el programa. La idea es que la propuesta sea lo más flexible y adaptable posible. En los anexos a este artículo, se desarrollan cada una de las seis lecciones propuestas que se van a enmarcar en cada una de las etapas del Camino de Santiago inglés.

\subsection{Verificación de la propuesta según el método IBI}

A continuación, se realizará un breve repaso de cada punto de la lista de verificación para comprobar que todas las lecciones incluidas en anexos cumplen los requisitos específicos de esta metodología de aprendizaje de vocabulario:

1. He identificado el vocabulario meta y los materiales necesarios para las actividades. Tanto el vocabulario meta como los materiales están especificados al principio de cada una de las lecciones. Hay unos materiales comunes a todas las lecciones, como, por ejemplo, las conchas del peregrino, que están señalados con anterioridad en este mismo apartado. 
2. He diseñado las actividades para que sean significativas, educativas e interactivas. Todas las actividades planteadas están enfocadas en este sentido, en línea con el objetivo principal de cada lección de aumentar la adquisición y retención de vocabulario.

3. He incluido información cultural e histórica cuando es apropiado. Desde el principio de la propuesta se incluye información cultural e histórica, en este caso, sobre el Camino de Santiago. Asimismo, cada lección contiene un paso, que suele ser el primero, en el que se contextualiza la etapa del camino incluyendo este tipo de información.

4. Me he asegurado de que el vocabulario meta se presenta primero de forma repetida en el input. Cada lección cuenta con al menos tres pasos en los que se hace hincapié en las palabras meta en el input, presentándolas de forma repetida.

5. He incrementado de forma progresiva la dificultad de las tareas que requieren vocabulario meta. En todas las lecciones se cumple este principio, ya que en los primeros pasos no se pide ningún tipo de producción o elaboración semántica, y en los siguientes sí.

6. He incorporado varios de los principios del método IBI. El primer principio se cumple con el plan de desarrollo de vocabulario guiado por el manual En Vocabulario. Medio B1 de Baralo et al. (2009). El resto de principios, excepto el 5 y el 8, se cumplen en todas las lecciones diseñadas. El principio número 5, presentar nuevas palabras de forma llamativa, se cumple en las lecciones 3 y 4 , en los pasos 3 y 2, respectivamente. En cuanto al principio número 8 , promover progresivamente el aprendizaje de los significados y usos de las palabras que sean específicas de la L2, se cumple en la lección 3 en el paso 4.

7. He aplicado resultados de estudios con implicaciones directas para la enseñanza de vocabulario. En todas las lecciones diseñadas se aplican resultados de investigaciones para la enseñanza de vocabulario relacionados con la gamificación (Lui, 2014; Llerena Medina y Rodríguez Hurtado, 2017; Kétyi, 2016). Asimismo, en el paso 3 de la lección 5, se aplica el uso de música de fondo al presentar vocabulario meta, como sugiere el estudio de de Groot en 2006 (en Barcroft, 2012: 39).

\section{Conclusiones}

Teniendo en cuenta lo expuesto en los anteriores apartados, podemos concluir que un acercamiento al aprendizaje de vocabulario en segundas lenguas a través de la gamificación puede resultar efectivo y de utilidad para las clases de ELE. Aunque de momento no son muchos los estudios empíricos llevados a cabo a este respecto, los resultados son halagüeños, suponiendo, en su mayoría, un incremento de la motivación y del compromiso, y con resultados académicos esperanzadores en la adquisición de segundas lenguas.

La propuesta no solo se fundamenta en dos metodologías innovadoras e interesantes por su aplicación práctica, como el método IBI y la gamificación, sino que además resulta flexible y realizable para su aplicación en el aula. En este sentido, se puede adaptar a otros niveles, utilizando otras palabras meta, y cuenta con la posibilidad de que se aplique en cursos más extensos, pasando de seis etapas, que son las que contiene el Camino de Santiago inglés, hasta incluso treinta y ocho que contiene la vía de la plata. Además, es 
una propuesta económicamente viable para la mayoría de los contextos educativos, ya que los materiales que requiere son o bien comunes en la gran parte de aulas de aprendizaje de español como lengua extranjera, o bien de fácil adquisición o elaboración.

Por último, esta propuesta también es interesante al tratar de convertir el contexto del aula de una clase de español para extranjeros en un contexto atractivo para los aprendientes, superando otro tipo de enseñanzas tradicionales donde el aprendizaje se produce por mera transmisión unidireccional del profesor a los alumnos. En este caso, se trata de poner al estudiante en el centro de la educación, favoreciendo su interactividad y su participación en el desarrollo normal del programa educativo.

\section{Bibliografía}

ABrams, S. S. y WALSH, S. (2015). «Gamified vocabulary», Journal of Adolescent \& Adult Literacy, 58(1), 49-58. DOI: https://doi.org/10.1002/jaal.315

AlONSO TAPIA, J. (2005). «Claves para la enseñanza de la comprensión lectora», Revista de Educación, núm. extraordinario, 63-93.

BAldauf, M., Brandner, A. y Wimmer, C. (2017). «Mobile and gamified blended learning for language teaching: studying requirements and acceptance by students, parents and teachers in the wild». En Proceedings of the 16th International Conference on Mobile and Ubiquitous Multimedia (pp. 13-24). Nueva York: ACM.

Baralo, M., Genís, M. y Santana, M. E. (2009). En Vocabulario. Medio B1. Madrid: Anaya - ELE.

BARCROFT, J. (2012). Input-Based Incremental Vocabulary Instruction. Alexandria, Virginia: TESOL International Association.

BARCROFT, J. (2015). «El método IBI en la enseñanza del léxico: teoría, investigación y nuevas perspectivas», Journal of Spanish Language Teaching, 2(2), 112-125. DOI: https://doi.org/10.1080/23247797.2015.1105512

Boers, F. y LindstromberG, S. (2009). Optimizing a lexical approach to instructed second language acquisition. Basingstoke: Palgrave Macmillan UK.

BuCKLeY, P. y Doyle, E. (2016). «Gamification and student motivation». Interactive Learning Environments, 24 (6), 1162-1175. DOI: https://doi.org/10.1080/10494820 .2014 .964263

CANTADOR, I. (2016). «La competición como mecánica de gamificación en el aula: una experiencia aplicando aprendizaje basado en problemas y aprendizaje cooperativo». En R. Contreras, y J.L. Eguia (ed.); Gamificación en aulas universitarias (pp. 68-97). Bellaterra: Institut de la Comunicació, Universitat Autònoma de Barcelona.

CASTAÑEDA, D.A. y CHO, M. (2016). «Use of a game-like application on a mobile device to improve accuracy in conjugating Spanish verbs», Computer Assisted Language Learning, 29 (7), 1195-1204. DOI: https://doi.org/10.1080/09588221.2016.1197950

DALMASES, A. (2017). «Uso de la gamificación en la enseñanza de ELE». E-eleando: Ele en Red. Serie de monografias y materiales para la enseñanza de ELE, 4, 1-74. 
Dehghanzadeh, H., Fardanesh, H., Hatami, J., Talaee, E. y Noroozi, O. (2019). «Using gamification to support learning English as a second language: a systematic review», Computer Assisted Language Learning, 1-24. DOI: https://doi.org/10.1080/ 09588221.2019 .1648298

DENNY, P. (2013). «The effect of virtual achievements on student engagement». En Proceedings of the SIG CHI conference on human factors in computing systems (pp. 763772). Nueva York: ACM.

Domínguez, A., Saenz-De-Navarrete, J., De-Marcos, L., Fernández-Sanz, L., PAGÉS, C. y MARTÍNEZ-HERRÁIZ, J. J. (2013). «Gamifying learning experiences: practical implications and outcomes». Computers \& Education, 63, 380-392. DOI: https://doi.org/10.1016/j.compedu.2012.12.020

FASLI, M. y MiCHALAKOPOULOS, M. (2005). «Supporting active learning through gamelike exercises». En Proceedings of the 5th IEEE International Conference of Advanced Learning Technologies (pp. 730-734). Kaohsiung: IEEE.

Gallego, F.J., Villagrá, C.J., Satorre, R., Compañ, P., Molina, R. y Llorens, F. (2014). «Panorámica: serious games, gamification y mucho más», ReVisión, 7(2), 13-23.

HAKUlinen, L., AUVINEN, T., y KorHONEN, A. (2013). «Empirical study on the effect of achievement badges in TRAKLA2 online learning environment», Learning and teaching in computing and engineering, 47-54.

HASEGAWA, T., KoSHINO, M., y BAN, H. (2015). «An English vocabulary learning support system for the learner's sustainable motivation», SpringerPlus, 4(1), 99. DOI: https://doi.org/10.1186/s40064-015-0792-2

KAPP, K. M. (2012). The gamification of learning and instruction: game-based methods and strategies for training and education. San Francisco: Pfeiffer.

KÉTYI, A. (2016). «From mobile language learning to gamification: an overlook of research results with business management students over a five-year period», Porta Linguarum, 1, 45-59.

LAM, S., Yim, P., LAW, J. y CHEUNG, R. (2001). «The Effects of Classroom Competition on Achievement Motivation». En Proceedings of the 109th Annual Conference of American Psychological Association. Recuperado el 17 de noviembre de 2019, de: http://página-web https://files.eric.ed.gov/fulltext/ED458511.pdf

LANDERS, R.N. Y LANDERS A.K. (2014). «An empirical test of the theory of gamified learning: the effect of leaderboards on time-on-task and academic performance», Simulation \& Gaming, 45(6), 769-785. DOI: https://doi.org/10.1177/1046878114563662

LAWRENCE, R. (2004). «Teaching data structures using competitive games», IEEE Transactions on Education, 47(4), 459-466.

LEWIS, M. (1993). The lexical approach. Hove: Language teaching publications.

Llerena Medina, E. G. y Rodríguez Hurtado, C. P. (2017). «Kahoot! A digital tool for learning vocabulary in a language classroom», Revista Publicando, 4 (12(1)), 441449.

LUI, S. (2014). «Use of gamification in vocabulary learning: a case study in Macau». En $\mathrm{X}$. Deng y R. Seow (ed.); Alternative pedagogies in the English language and 
communication classroom (pp. 90-97). Singapore: Centre for English Language Communication, National University of Singapore.

NAtTinger, J. R. y De CARrico, J.S. (1992). Lexical Phrases and Language Teaching. Oxford: Oxford University Press.

Ortiz-Colón, A.M., JordÁn, J. y AgredAl, M. (2018). «Gamificación en educación: una panorámica sobre el estado de la cuestión», Educ. Pesqui., São Paulo, 44, 1-17. DOI: http://dx.doi.org/10.1590/S1678-4634201844173773

Simões, J., DíAz REDONDO, R. y FERnÁNDEZ ViLAS, A. F. (2013). «A social gamification framework for a K-6 learning platform», Computers in Human Behavior, 29(2), 345-353. DOI: https://doi.org/10.1016/j.chb.2012.06.007

SORIANO, M.M. (2001). «La motivación, pilar básico de todo tipo de esfuerzo», Proyecto social: Revista de relaciones laborales, 9, 163-184.

Stott, A. y NeUSTAedTER, C. (2013). Analysis of gamification in education. Surrey: Simon Fraser University.

VAN ECK, R. (2006). «Digital game-based learning: It's not just the digital natives who are restless», EDUCAUSE review, 41(2), 1-16.

VOCKELL, E. (2004). Educational psychology: a practical approach. Indiana: Purdue University.

WERBACH, K. y HUNTER, D. (2012). For the win: how game thinking can revolutionize your business. Philadelphia: Wharton Digital Press.

WiLLIS, D. (1990). The lexical syllabus. London: Collins.

ZHOU, L., YU, J. y SHI, Y. (2017). «Learning as adventure: an app designed with gamification elements to facilitate language learning». En F. Nah y C.H. Tan (ed.); HCI in Business, Government and Organizations. Interacting with Information Systems. 4th International Conference, HCIBGO 2017, Held as Part of HCI International 2017, Vancouver, BC, Canada, July 9-14, 2017, Proceedings, Part I (pp.266-275). Cham: Springer International Publishing AG.

\section{Webgrafía}

OTEIZA, B. (s,f). Hogarmanía. Recuperado el 24 de agosto de 2019 de: https://www.hogarmania.com/cocina/recetas/aperitivos/201209/pulpo-gallega-patatas16305.html

PARQUEESPANA (16 de agosto de 2013). Recuperado el 12 de noviembre de 2019 de: https://www.youtube.com/watch?v=vBNwZY5w_as

PilgRiM (s,f). Recuperado el 24 de agosto de 2019 de: https://www.pilgrim.es

VIVE EL CAMINO (s,f). Recuperado el 24 de agosto de 2019 de: https://vivecamino.com 


\section{Anexos}

\section{Lección 1. Etapa 1: Ferrol - Neda (15 km)}

Palabras meta: receta, ingredientes, plato, alimento, cocer, freír, crudo, cocinar, pimentón, tomar, picante, sal, pulpo, caliente, frío, asustar, menú, entrante, marisco, sabor, y otras palabras que puedan surgir en el trascurso de la lección.

Materiales: ordenador con proyector.

Paso 1. Ponga a los estudiantes en situación contándoles un poco sobre la primera etapa del viaje. Trate de incluir tantas palabras meta como sea posible e imágenes sobre la ciudad de origen y el camino. El input debe ser comprensible y se debe favorecer que los estudiantes puedan preguntar las palabras que desconozcan. Por ejemplo: Nuestro viaje empieza en Ferrol, una ciudad portuaria históricamente muy ligada al mar. Su puerto, protegido por tres castillos, ha sido testigo de miles de peregrinos que venían a emprender su viaje a Santiago. La primera etapa consiste en $15 \mathrm{~km}$ de distancia, la etapa más corta de las que vamos a hacer.

Al ser una ciudad muy ligada al mar, la pesca en Ferrol ha sido muy importante y, de ahi, que platos como el pulpo a la gallega o las empanadas de marisco sean típicos de esta ciudad. El pulpo a la gallega es un plato típico de toda la comunidad, ya que es una receta elaborada con ingredientes propios de la zona. Es un plato que se puede tomar tanto caliente como frío, dependiendo de cada uno, y que lleva pimentón, sal, aceite de oliva y patatas.

Paso 2. Pida a los estudiantes ver un breve vídeo sobre la elaboración del pulpo a la gallega. Puede utilizar un vídeo de hogarmanía en el que Bruno Oteiza prepara una receta de pulpo a la gallega con patatas. El vídeo es el siguiente:

\section{https://www.hogarmania.com/cocina/recetas/aperitivos/201209/pulpo-gallega-patatas- $\underline{16305 . h t m l}$}

Paso 3. Pregunte a los estudiantes si hay alguna palabra que no entiendan. Si hay alguna, anime a que otro estudiante pueda ayudarle y, sino, proporcione el significado usted mismo. Una vez resueltas las dudas, pregunte a los estudiantes sobre el vídeo usando el mayor número de palabras meta posibles. Por ejemplo: ¿Cuántos ingredientes son necesarios para preparar esta receta? ¿Podrías decirnos cuáles?; ¿Para qué asusta el cocinero al pulpo?; ¿Qué otros tipos de marisco conoces a parte del pulpo?

Paso 4. Defina todas las palabras meta con un vocabulario comprensible y dando ejemplos de cada una de ellas, incluyendo otros miembros de la misma familia de palabras. Por ejemplo: Alimento se refiere a aquello que los seres vivos comen y beben para mantenerse con vida. Alimentarse es una necesidad vital pero también tienen un componente social para los seres humanos. Una buena alimentación puede ser muy beneficiosa para la salud. Este es el significado de alimento. Repita la palabra definida al terminar la explicación y permita a los estudiantes que puedan hacer preguntas.

Paso 5. Pregunte a los estudiantes sobre los distintos platos típicos que hay en sus países. Apunte todos los platos y cada palabra nueva de vocabulario que salga, explicándola a los estudiantes en términos sencillos. Deles más ejemplos de comidas típicas españolas. ¿Qué diferencias principales encuentran entre sus platos típicos y los españoles? 
Paso 6. Como actividad fuera de clase, pida a los grupos formados para el juego que se pongan de acuerdo en hacer una receta típica del país de uno de ellos y traerla a clase el día siguiente. Tendrán que presentarla ante sus compañeros especificando qué ingredientes lleva, cuál es su modo de preparación y qué origen tiene.

Paso 7. En la siguiente clase, cada grupo presentará su plato y se llevará a cabo una cata de la misma. Cada equipo puede ganar una concha del peregrino de oro, de plata o de bronce, basada en la presentación del plato. No hay ganadores ni perdedores en esta prueba, ya que para conseguir el oro, la plata, o el bronce solo dependen de ellos mismos como grupo. Por ejemplo, todos pueden obtener la concha de oro si hacen bien el trabajo. Si un grupo no puede traer un plato cocinado, entonces pueden hacer la presentación igual que el resto con imágenes de fondo, sin ser penalizados por ello de ninguna forma.

\section{Lección 2. Etapa 2: Neda - Pontedeume (16 km)}

Palabras meta: turismo, albergue, plano, alojamiento, viaje, aventura, naturaleza, mochila, saco de dormir, manta, rural, hoteles, montaña, vacaciones, monumento, museo, valor histórico, descansar, tranquilidad, y otras palabras que puedan surgir en el trascurso de la lección.

Materiales: ordenador con proyector, tarjetas con palabras meta.

Paso 1. Informe a los estudiantes de que la lección del próximo día va a tratar sobre viajes y alojamientos. En la pizarra, o en un proyector, exponga las 20 palabras meta de la lección. Asigne a cada uno de los estudiantes una o dos palabras para que expongan su definición en la siguiente clase utilizando ejemplos. Como instrucción, dígales que usen la palabra, u otros miembros de la misma familia, un mínimo de cinco veces.

Paso 2. Ponga a los estudiantes en situación contándoles un poco sobre la segunda etapa del viaje, usando tantas palabras meta como sea posible. Al igual que en la anterior lección, les pondremos imágenes del camino. El input usado debe ser comprensible y se debe favorecer la interacción de los estudiantes para que puedan preguntar sobre aquellas palabras que no entiendan. Por ejemplo: La segunda etapa de nuestro camino comienza en Neda, una población de la provincia de La Coruña con algo más de 5.000 habitantes. Neda es una población de origen medieval con un gran valor histórico muy cercana al Camino de Santiago. La Casa da Cultura de Neda es un museo donde se pueden encontrar mucha información sobre el camino. Salvo alguna pendiente, esta etapa es bastante sencilla, transcurre muy próxima a la carretera donde podemos encontrar bastantes restaurantes donde poder comer y albergues donde poder descansar (www.pilgrim.es). Al ser una población tranquila, rodeada de naturaleza, es un lugar ideal para descansar antes de continuar con el viaje.

Paso 3. Una vez puestos en contexto, deje que los estudiantes lleven a cabo sus presentaciones. Asístales en el caso de que necesiten ayuda, bien con la pronunciación o bien con el significado.

Paso 4. Proyecte en una pantalla una lista de 20 definiciones de las palabras meta que acaban de presentar. En una hoja en blanco, dígales que escriban la palabra correspondiente a cada una de las definiciones numeradas en la pantalla. 
Paso 5. Junte a los alumnos en parejas y dígales que comparen las respuestas y se pongan de acuerdo entre ellos. Pueden consultar cualquier duda al resto de la clase y, en último término, al profesor.

Paso 6. En esas mismas parejas, los alumnos compartirán, con el compañero, cuál ha sido el mejor viaje de su vida.

Paso 7. En la siguiente clase, junte a los alumnos en los grupos del juego y explíqueles la actividad a realizar para conseguir las conchas de oro, plata y bronce. Explicación de la actividad: en tarjetas, estarán apuntadas todas las palabras meta. El grupo inicial, que se decidirá a suertes, elegirá a uno de los componentes para empezar a jugar. Este miembro del equipo tendrá un minuto para dibujar a sus compañeros el número máximo de palabras meta que vayan saliendo en las tarjetas. Cuando el equipo acierte una palabra, se pasará a la siguiente. Para que no hagan trampas, el profesor estará al tanto de las palabras que vayan saliendo. Cuando se acabe el tiempo, será el turno del siguiente grupo, hasta que se acaben todas las palabras meta. Tendrán que ir cambiando de dibujante en cada ronda. Al terminar la partida, se preguntarán todas las dudas correspondientes a las palabras. El equipo que más palabras meta haya acertado obtendrá la concha de oro, el segundo y el tercero obtendrán la concha de plata, y el último la de bronce (en caso de ser cuatro equipos).

\section{Lección 3. Etapa 3: Pontedeume - Betanzos (20 km)}

Palabras meta: quedar bien, botas, pantalones, ajustado, ancho, talla, cómodo, tejido, arrugar, estar a la moda, rebajas, lavar la ropa, calzado, número, calidad, flexible, moderno, anticuado, movimiento, cinturón, y otras palabras que puedan surgir en el trascurso de la lección.

Materiales: ordenador con proyector, test, tarjetas con palabras meta.

Paso 1. Ponga a los estudiantes en contexto sobre la tercera etapa del Camino de Santiago que van a realizar, usando tantas palabras meta como sea posible con un input comprensible, imágenes del camino, y dejando tiempo para que puedan hacer preguntas. Por ejemplo: La tercera etapa del camino es una etapa un poco más larga, de $20 \mathrm{~km}$, y se inicia en Pontedeume, una villa costera de origen medieval. Es una de las etapas más dificiles del camino por su gran desnivel. Tendremos que hacer un gran esfuerzo, para lo cual es conveniente que hayamos traído pantalones que permitan un movimiento adecuado al caminar, unas buenas botas de nuestra talla que se ajusten bien a nuestro pie, y, en general, ropa cómoda. En esta lección vamos a hablar sobe qué tipo de ropa y calzado son adecuados para hacer el Camino de Santiago. Es importante llevar ropa adecuada para tantos días de camino. Una ropa y un calzado que no tienen por qué ser los que estén a la moda ni los que nos queden mejor, pero sí los que nos permitan caminar de forma más cómoda.

Paso 2. Proyecte imágenes de todas las palabras meta en la clase. De una en una imagen, explique a qué palabra meta se refiere haciendo todas las aclaraciones posibles sobre la palabra y preguntando a los estudiantes para una mayor interacción. Por ejemplo: Botas. Esta imagen muestra unas botas. Es un tipo de calzado especialmente adecuado para caminar en rutas de montaña. ¿Qué otro tipo de calzado conocéis a parte de las botas? Lavar la ropa. En esta imagen podéis ver una lavadora, que es el electrodoméstico que 
lava la ropa. En el Camino de Santiago es normal que la gente lave la ropa a mano para el día siguiente. ¿Cuánta ropa creéis adecuado llevar para nuestro camino que consta de seis etapas?

Paso 3. Una vez terminadas las explicaciones, vuelva a proyectar las imágenes de una en una diciendo a los estudiantes que traten de recordar su nombre sin decirlo en voz alta. Una vez proyectada la imagen durante unos cinco o seis segundos, acto seguido aparecerá, debajo de la misma, el nombre en un intervalo de tiempo menor, y justo después una voz diciéndolo en alto. Los estudiantes podrán confirmar si recordaban o no la palabra. Repita lo mismo con todas las palabras meta durante tres rondas.

Paso 4. Proporcione a los estudiantes otros significados claves de las palabras meta que no hayan salido en los pasos anteriores. Por ejemplo: Cómodo se puede referir a una ropa o a un asiento, pero también se puede estar cómodo en situaciones, o con gente. Botas es un tipo de calzado, pero hay expresiones como «me estoy poniendo las botas» que significa que estoy comiendo mucho y bien. Cinturón es un complemento para el pantalón que se puede usar en la expresión «hay que apretarse el cinturón», cuando tenemos que reducir los gastos.

Paso 5. Inicie un debate corto sobre la importancia de la ropa en las sociedades actuales. ¿Qué dice sobre nosotros la ropa que llevamos? ¿Dais mucha importancia a la forma en la que vestís?

Paso 6. Deles un test que contenga todas las palabras meta y sus definiciones para que tengan que emparejarlas de forma individual.

Paso 7. Júnteles en parejas y pídales comprobar sus respuestas. Cualquier duda que surja se dirá en alto en clase para que puedan ayudarles cualquiera de sus compañeros y, en último término, el profesor.

Paso 8. En la siguiente clase, junte a los alumnos en los grupos de juego para que puedan llevar a cabo la actividad puntuable. Explicación de la actividad: en tarjetas estarán apuntadas todas las palabras meta de la lección. Este juego consistirá en tres rondas distintas. En la primera ronda, el equipo inicial, elegido a suertes, tendrá que decidir un miembro del equipo para empezar a jugar. Este estudiante tendrá un minuto para definir a sus compañeros el número máximo de palabras meta que vayan saliendo en las tarjetas. Cuando el equipo acierte una palabra, se pasará a la siguiente, poniendo la tarjeta acertada al lado del equipo. Al igual que en el juego anterior, el profesor vigilará que no haya ninguna trampa. Cuando se acabe el tiempo, le tocará al siguiente equipo, que hará lo mismo, así hasta que se acaben todas las tarjetas meta, cambiando de participantes. En la segunda ronda, el mecanismo es el mismo, pero ahora lo que tendrán que hacer los estudiantes es decir una sola palabra para definir la palabra meta que contiene la tarjeta. En la tercera ronda, se hará lo mismo, pero esta vez con mímica. En cada ronda se irán contando los aciertos de cada equipo. De la misma forma que en la lección anterior, el equipo que más palabras meta haya acertado obtendrá la concha de oro, el segundo y el tercero obtendrán la concha de plata, y el último la de bronce (en caso de ser cuatro equipos). 


\section{Lección 4. Etapa 4: Betanzos - Bruma $(27,8$ km)}

Palabras meta: granja, huerta, invernadero, campesino, cultivar, plantar, hortalizas, arar, sembrar semillas, árboles frutales, toro, oveja, vaca, ordeñar, colmena, recolectar miel, abejas, regar, cortar ramas, y otras palabras que puedan surgir en el trascurso de la lección.

Materiales: ordenador con proyector, textos, tarjetas en blanco para las preguntas del trivial.

Paso 1. Ponga a los estudiantes en contexto sobre la cuarta etapa del viaje usando tantas palabras meta como sea posible e imágenes del camino. Para ello, utilice un input comprensible y deles la oportunidad de preguntar por las dudas que les vayan surgiendo. Por ejemplo: La etapa que vamos a realizar se inicia en Betanzos, una ciudad de aproximadamente 13000 habitantes. Es una ciudad declarada conjunto históricoartístico por sus monumentos góticos. Además, es famosa por su gastronomía, en especial, por la tortilla de patatas. Esta etapa es la más difícil del camino por su longitud, casi 30 kilómetros alejados de ciudades y pueblos, y por su desnivel. Es importante salir de Betanzos con suficiente comida y bebida para realizar el viaje, ya que el camino se hará principalmente por el campo y la naturaleza, tema que vamos a tratar en esta lección. Hablaremos sobre los animales de granja más frecuentes en Galicia, como son la vaca, el toro y la oveja, así como las abejas, imprescindibles para la recolección de miel. La zona de Galicia cuenta con huertas donde los campesinos siembran semillas variadas de árboles frutales y otros cultivos, como por ejemplo, viñas para el vino o pimientos de padrón.

Paso 2. Provee a cada estudiante con el siguiente fragmento de texto. Pida a un estudiante voluntario que lo lea en alto y ayúdele con la pronunciación en caso de ser necesario.

El fin de semana pasado fuimos a visitar una granja para conocer de cerca la vida en el campo; en la granja había un edificio principal, una huerta y un invernadero. Aprendimos muchas cosas de la vida rural; entre otras, que un campesino trabaja muchísimo. Fue muy divertido porque tuvimos la oportunidad de cultivar en la huerta, donde había plantado muchas hortalizas: zanahorias, tomates, cebollas, lechugas, etc. Aramos la tierra, sembramos semillas y después recogimos tomates, lechugas, cebollas, ajos y zanahorias para poder hacer una buena ensalada. ;Estaba riquísima! También plantamos árboles frutales, tres perales y dos manzanos. Habia toros y ovejas en el prado, comiendo hierba. Al atardecer ordeñamos las vacas para tener leche para el desayuno. Además, nos enseñaron cómo hacen yogur, queso y mantequilla con la leche. Al día siguiente, fuimos a unas colmenas a recolectar miel. Nos pusimos guantes y una especie de sombrero para que no nos picaran las abejas. La temperatura cálida del invernadero favorece el cultivo de las plantas. Nosotros regamos las plantas, cortamos ramas e hicimos ramos para colocar en floreros.

Cuando nos fuimos, inos regalaron los ramos que habiamos hecho para que nos los lleváramos a casa! Nos ha gustado mucho la experiencia y sin duda a repetiremos el año que viene.

Texto modificado de En Vocabulario. Medio B1 En Vocabulario. (Baralo et al., 2009: 113) 
Paso 3. Cada estudiante, por su cuenta, tratará de inferir por el contexto el significado de las palabras en negrita.

Paso 4. Proyecte las definiciones de cada una de las palabras meta, en negrita en el apartado anterior, en la clase. Junte a los alumnos en parejas para que traten de averiguar a qué definición corresponde cada palabra.

Paso 5. Retire los textos y compruebe palabra por palabra si han sido capaces de captar los significados de cada una de ellas, repitiendo cada una al menos tres veces.

Paso 6. Provee a cada estudiante con el mismo texto, pero esta vez tendrán que rellenar los espacios en blanco, que corresponden a las palabras meta. Una vez tengan hecho el ejercicio, diles que se junten en las mismas parejas para que puedan poner en común sus respuestas.

El fin de semana pasado fuimos a visitar una para conocer de cerca la vida en el campo; en la granja había un edificio principal, una y un

Aprendimos muchas cosas de la vida rural; entre otras, que un muchísimo. Fue muy divertido porque tuvimos la oportunidad de trabaja donde muchas en la huerta, lechugas, etc. la tierra, : zanahorias, tomates, cebollas, y después recogimos tomates, lechugas, cebollas, ajos y zanahorias para poder hacer una buena ensalada. iEstaba riquísima! También plantamos tres perales y dos manzanos. Había $y$ en el prado, comiendo hierba. Al atardecer las para tener leche para el desayuno. Además, nos enseñaron cómo hacen yogur, queso y mantequilla con la leche. Al día siguiente, fuimos a unas $a$

Nos pusimos guantes y una especie de sombrero para que no nos picaran las . $L a$ temperatura cálida del invernadero favorece el cultivo de las plantas. Nosotros las plantas, e hicimos ramos para colocar en floreros.

Cuando nos fuimos, inos regalaron los ramos que habiamos hecho para que nos los lleváramos a casa! Nos ha gustado mucho la experiencia y sin duda a repetiremos el año que viene.

Texto modificado de En Vocabulario. Medio B1 En Vocabulario. (Baralo et al., 2009: 113)

Paso 7. Pregunte a los estudiantes cuánto saben sobre el desarrollo de la agricultura y la ganadería en la sociedad, su importancia y su situación actual, y lleven a cabo un breve debate sobre el tema. Apunte en la pizarra cualquier nueva palabra que aparezca y explique su significado poniendo ejemplos.

Paso 8. Como tarea para realizar antes de la siguiente clase, cada grupo del juego va a tener que elaborar una parte del trivial que se va a realizar en la misma. Pida a cada grupo que haga una pregunta relacionada con cada una de las cinco palabras meta que se le asigne. El profesor traerá, a parte, dos preguntas suyas por cada palabra meta. Todas las preguntas tienen que ser fácilmente comprensibles por la clase. Por ejemplo: ¿Eres capaz de nombrar al menos un árbol frutal? ¿Qué animal produce la miel que recolectamos? ¿Qué diferencia una huerta de un invernadero? ¿Qué animales ordeñamos para producir leche para el consumo humano? ¿Dónde viven las abejas? ¿Eres capaz de nombrar al menos una herramienta que ayude al ser humano a trabajar el campo?

Paso 9. En la siguiente clase, junte a los alumnos en los grupos de juego para que puedan realizar la actividad puntuable, el trivial que han elaborado entre todos. Pídales las 
preguntas que han realizado y explique la actividad. El profesor barajará todas las preguntas, incluidas las suyas, e irá preguntando grupo por grupo a ver si saben la respuesta. Si el grupo al que pregunta falla, el rebote será para el primer grupo que levante la mano justo después. Si nadie sabe la respuesta, el profesor la explicará, y esa tarjeta quedará fuera del juego. Al igual que en el juego anterior, el equipo que más respuestas haya acertado obtendrá la concha de oro, el segundo y el tercero obtendrán la concha de plata, y el último la de bronce (en caso de ser cuatro equipos).

\section{Lección 5. Etapa 5: Bruma - Sigüeiro (24 km)}

Palabras meta: danza, baile, gaita, pandereta, instrumento musical, percusión, traje tradicional, pieza musical, instrumentos de viento, instrumentos de cuerda, sonido, vibrar, soplar, tocar, ensayar, cantar, componer, música, jota, folclore, y otras palabras que puedan surgir en el trascurso de la lección.

Materiales: ordenador con proyector, test, sobres con las pruebas del juego.

Paso 1. Ponga a los estudiantes en contexto con información sobre la quinta etapa del camino inglés que estamos llevando a cabo, usando tantas palabras meta como sea posible e imágenes del camino. Para ello, utilice un input comprensible y deles la oportunidad de preguntar por las dudas que les vayan surgiendo. Por ejemplo: Esta cuarta etapa del camino inglés es una epata mucho más fácil que las anteriores, ya que el terreno es llano. Además, hay muchos servicios hosteleros que pueden sernos de utilidad tanto para comer como para beber. La etapa se inicia en Bruma, una pequeña localidad muy tranquila que contaba con un antiguo hospital de peregrinos, ya desaparecido. En estas pequeñas localidades gallegas el folclore es muy importante. Como parte fundamental del mismo, tenemos la muñeira. La muñeira es una danza popular que se baila en la comunidad autónoma de Galicia, y en las zonas más cercanas de Castilla y León, y Asturias. Se cree que procede de bailes celtas y que nace en el siglo XVI. La palabra «muñeira» deriva de la palabra gallega «muiños», que significa molinos, ya que se solia bailar en los molinos para hacer más llevadera la jornada de trabajo. La muñeira es una danza que se bailay se canta acompañada, normalmente, de gaitas, panderetas y otros instrumentos de percusión. Es una danza que se suele bailar en parejas, pero si el número de bailarines es superior a seis, se puede bailar en círculo. Los bailarines visten con el traje tradicional de la región. La muñeira más famosa es la «Muñeira de la Chantada», una pieza musical que vamos a escuchar a continuación.

Paso 2. Proyecte un vídeo de la «Muñeira de la Chantada» en Youtube. Puede utilizar el siguiente:

\section{https://www.youtube.com/watch? $v=v B N w Z Y 5 w$ as}

Paso 3. Informe a los estudiantes de que esta lección va a versar sobre la música y la danza. Para facilitarles su realización, léales lentamente y con buena pronunciación las 20 palabras meta de la misma. Pídales que presten atención y que intenten recordarlas. Pronuncie cada una de las palabras claramente y de forma lenta, y deles algunos segundos para que la memoricen. Durante este paso, ponga música de fondo sin voz, por ejemplo, música clásica.

Paso 4. Ahora pase a dar a los estudiantes definiciones de las palabras meta ilustrándolas con ejemplos en la medida de lo posible. Cada definición de la palabra meta debe ser 
comprensible y contener otras palabras de la misma familia. A la vez que empiece a definirlas, escríbelas en la pizarra de la clase para que las tengan visibles. Por ejemplo: La danza o baile es un arte en el que los participantes se mueven al ritmo de la música. Aquellos que practican el baile se llaman bailarines. Hay muchos tipos de baile, desde el más clásico hasta el contemporáneo, de salón o tradicionales, como la muñeira. Instrumentos de viento. Es una familia de instrumentos musicales que producen sonido por la vibración del aire en su interior. Dentro de esta familia de instrumentos de viento tenemos el saxofón, el clarinete, la flauta, y muchos más.

Paso 5. Proporcione a los estudiantes un folio con dos test a realizar, uno por cada cara del mismo. En la primera cara, tendrán a un lado una columna con palabras meta y al otro lado una columna con definiciones. Tendrán que marcar qué definición corresponde con cada palabra meta. Una vez realizado, ponga en común con la clase sus respuestas y corrija el test en clase. Al acabar este primer test, pídales que den la vuelta al folio. En el otro lado se encontrarán con todas las definiciones de las palabras metas. Su tarea será escribir a un lado las palabras a las que se corresponde cada definición. Corrija en común las respuestas.

Paso 6. Pida a los estudiantes, como actividad fuera de clase, que realicen una breve redacción sobre su grupo de música favorito. Pídales que incluyan al menos cinco palabras meta de las veinte.

Paso 7. Cada estudiante leerá su breve redacción delante de la clase. Aproveche para definir nuevas palabras que vayan surgiendo.

Paso 8. Junte a los alumnos en los grupos del juego y explíqueles la actividad que tendrán que hacer para conseguir las conchas de oro, plata o bronce. En este caso se trata de una gincana que va a constar de cuatro pruebas. Cada prueba que vayan resolviendo los grupos tendrá que ser verificada con el profesor. Si la solución es correcta, podrán pasar a realizar la siguiente prueba, que les dará el profesor en un sobre. En esta actividad lo importante será el tiempo. Dispondrán de una hora. Todo el que llegue al final antes de ese tiempo obtendrá la concha de oro. Los que lleguen a la prueba cuatro, la de plata. Y los que no pasen de la prueba tres o inferior, la de bronce.

- Prueba 1. Un acróstico. Por ejemplo:

\section{Muñeira}

Una danza gallega

que se baila y se

canta con

incómodos trajes

pero con muchas

ganas y alegría.

\section{(Respuesta: Música.)}

- Prueba 2. Un mensaje oculto dentro de unas imágenes. En cada imagen habrá una letra escondida para que puedan formar la palabra requerida. Por ejemplo, gaita.

- Prueba 3. Una prueba criptográfica similar a la escítala usada por los espartanos. Consiste en lo siguiente: se escribe un mensaje en una cinta alargada que solo se pueda leer si lo enrollas a un cilindro. Aparentemente la 
cinta solo tendrá letras al azar, pero al enrollarlo al cilindro adecuado, se podrá leer el mensaje. Para ello, se dejará una cinta y dos tipos de cilindros por la clase, que pueden ser un rollo de papel higiénico y un rollo de cocina. Solo se leerá el mensaje enrollándolo en el correcto. Ese mensaje será una de las palabras meta, por ejemplo, pieza musical.

- Prueba 4. Enigma musical. En mi caja de música entran muchas cosas, pero hay otras muchas que no. En mi caja de música entra una silla y un sofá, pero no entra una butaca. Entra la música pero no entra una canción. Podría meter el sol, pero no cabe la luna. En mi caja de música entra un regalo, una lámpara, pero no un cuaderno y ni siquiera un pequeño pendiente. ¿Sabrías decirme qué cosas entran en mi caja de música? La respuesta es: entra todo aquello cuyas sílabas contengan una letra musical. Se pueden poner muchos más ejemplos para ayudarles a resolverlo cuanto antes.

\section{Lección 6. Etapa 6: Sigüeiro - Santiago de Compostela (16,7 km)}

Palabras meta: iglesia, catedral, escultura, muralla, puente, monasterio, castillo, mezquita, sinagoga, templo, arquitectura, estatua, plaza, exposición, barroco, románico, gótico, construir, universidad, casco antiguo, y otras palabras que puedan surgir en el trascurso de la lección.

Materiales: ordenador con proyector, hojas con preguntas, dispositivos de grabación (cámaras o móviles), tarjetas de los premios de cine.

Paso 1. Ponga a los estudiantes en contexto con información sobre la sexta etapa del camino inglés que estamos llevando a cabo, usando tantas palabras meta como sea posible e imágenes del camino. Para ello, utilice un input comprensible y deles la oportunidad de preguntar por las dudas que les vayan surgiendo. Por ejemplo: Última etapa del camino inglés y la más fácil de todas. Se visualizan las torres de la catedral, a tan solo cuatro horas de camino. El acceso a la ciudad no es el mejor, pero pronto podremos ver el casco antiguo, que cuenta con numerosos templos de culto cristiano, iglesias y la catedral. La llegada a la impresionante Catedral de Santiago, de estilos románico, gótico y barroco marca el final del camino. Atrás dejamos los pequeños pueblos por los que hemos caminado y llegamos a una ciudad con un casco antiguo declarado patrimonio de la Humanidad por la UNESCO. La Plaza del Obradoiro es el corazón de esta ciudad. Su nombre se refiere al taller u obrador («obradoiro», en gallego) de canteros que funcionaba en la plaza durante la construcción de la catedral.

Paso 2. Proyecte imágenes de cada una de las palabras meta. De una en una imagen, explique a qué palabra meta se refiere haciendo todas las aclaraciones posibles sobre la palabra, y preguntando a los estudiantes para una mayor interacción. Por ejemplo: Iglesia. Esta imagen muestra una iglesia. Las iglesias son templos de oración cristiana. ¿Conocéis el nombre de los templos de oración musulmanes y judios? Muralla. En esta imagen podéis ver la muralla de Ávila, una de las mejores conservadas de la península ibérica. Las murallas son construcciones que servían para defender la ciudad de los enemigos. ¿Conocéis alguna otra ciudad que conserve su muralla en la actualidad?

Paso 3. Vuelva a proyectar de nuevo las imágenes, de una en una, diciendo a los estudiantes que traten de recordar su nombre y lo escriban en un folio en blanco. Una vez pasen cinco o seis segundos, diga usted mismo el nombre en voz alta y escríbalo en la 
pizarra para que puedan comprobar si lo tienen bien escrito. En caso de haber fallado, pídales que lo escriban de nuevo de forma correcta.

Paso 4. Junte a los alumnos en grupos de tres. Deles una hoja con veinte preguntas, cada una referente a una de las palabras meta. Pueden usar un dispositivo móvil para encontrar las respuestas en internet. Deles un máximo de un minuto por pregunta. Ejemplo de preguntas:

- ¿En qué año se inauguró la Catedral de Santiago?

- ¿Cuál es la diferencia principal entre iglesia y catedral?

- ¿Eres capaz de decirnos tres monumentos del románico español?

- ¿Cuál es el castillo más antiguo de España? ¿Y de Europa?

- ¿Cuál es el nombre de las escrituras sagradas del islam que se leen en las mezquitas?

Paso 5. Ponga las respuestas en la pantalla del proyector para que puedan comprobar si sus respuestas son correctas. Abra un pequeño debate sobre si es bueno que las sociedades tengan muy presente su pasado y se esfuercen en conservarlo y estudiarlo, o si es mejor que miren hacia el presente y el futuro, dando menos importancia al pasado. Apunte en la pizarra cualquier palabra nueva que surja.

Paso 6. Como tarea para realizar antes de la siguiente clase, pida a cada grupo del juego que se junte para elaborar un pequeño guion para hacer un cortometraje audiovisual de entre tres y cinco minutos. En este corto tendrán que usar un mínimo de cinco palabras meta. El tema es libre, pero para que les sea más fácil, propóngales varios ejemplos que puedan usar. Por ejemplo: origen del Camino de Santiago, real o inventado; fundación de la ciudad de Santiago de Compostela, real o inventada; Picasso en la ciudad de Coruña.

Paso 7. Cada grupo de juego irá presentando uno a uno el borrador del guion al profesor para que pueda ayudarles. Todos los grupos seguirán trabajando hasta tener el guion definitivo.

Paso 8. Una vez realizado el guion, el grupo tendrá que grabar el vídeo, ya sea con una cámara o con el móvil.

Paso 9. En la siguiente clase, se proyectarán los vídeos de todos los grupos. Cada uno de los grupos tendrá que hacer una breve introducción del mismo y, tras la proyección, contestar a las preguntas que puedan surgir por parte del profesor y del resto de la clase.

Paso 10. Al finalizar el pase de cortos, se les entregará una tarjeta a cada grupo para que valore los cortos de los demás grupos. En esta tarjeta, tendrán que escribir cuál es su favorito para ganar cada uno de las siguientes categorías: mejor película, mejores interpretaciones y mejor puesta en escena. Los ganadores de cada una de las categorías se llevarán la concha de oro. El resto de cortometrajes, que cumplan con los requisitos de duración y palabras meta, y sean comprensibles, ganarán una concha de plata. Si hay algún cortometraje que no cumple con las condiciones anteriores obtendrá una concha de bronce. 


\begin{tabular}{|l|l|}
\hline \multicolumn{2}{|l|}{ PREMIOS SANTIAGO DE CINE } \\
\hline MEJOR PELÍCULA & \\
\hline MEJORES INTERPRETACIONES & \\
\hline MEJOR PUESTA EN ESCENA & \\
\hline
\end{tabular}

